\title{
Targeting COX-2 and EP4 to control tumor growth, angiogenesis, lymphangiogenesis and metastasis to the lungs and lymph nodes in a breast cancer model
}

\author{
Xiping Xin ${ }^{1}$, Mousumi Majumder ${ }^{1}$, Gannareddy V Girish¹, Vik Mohindra ${ }^{1}$, Takayuki Maruyama ${ }^{2}$ and \\ Peeyush K Lala ${ }^{1,3}$
}

We reported that cyclo-oxygenase (COX)-2 expression in human breast cancer stimulated cancer cell migration and invasiveness, production of vascular endothelial growth factor (VEGF)-C and lymphangiogenesis in situ, largely from endogenous PGE2-mediated stimulation of prostaglandin E (EP)1 and EP4 receptors, presenting them as candidate therapeutic targets against lymphatic metastasis. As human breast cancer xenografts in immuno-compromised mice have limitations for preclinical testing, we developed a syngeneic murine breast cancer model of spontaneous lymphatic metastasis mimicking human and applied it for mechanistic and therapeutic studies. We tested the roles of COX-2 and EP receptors in VEGF-C and -D production by a highly metastatic COX-2 expressing murine breast cancer cell line C3L5. These cells expressed all EP receptors and produced VEGF-C and -D, both inhibited with COX-2 inhibitors or EP4 (but not EP1, EP2 or EP3) antagonists. C3H/HeJ mice, when implanted SC in both inguinal regions with C3L5 cells suspended in growth factor-reduced Matrigel, exhibited rapid tumor growth, tumor-associated angiogenesis and lymphangiogenesis (respectively measured with CD31 and LYVE-1 immunostaining), metastasis to the inguinal and axillary lymph nodes and the lungs. Chronic oral administration of COX-1/COX-2 inhibitor indomethacin, COX-2 inhibitor celecoxib and an EP4 antagonist ONO-AE3-208, but not an EP1 antagonist ONO-8713 at nontoxic doses markedly reduced tumor growth, lymphangiogenesis, angiogenesis, and metastasis to lymph nodes and lungs. Residual tumors in responding mice revealed reduced VEGF-C and -D proteins, AkT phosphorylation and increased apoptotic/proliferative cell ratios consistent with blockade of EP4 signaling. We suggest that EP4 antagonists deserve clinical testing for chemo-intervention of lymphatic metastasis in human breast cancer.

Laboratory Investigation (2012) 92, 1115-1128; doi:10.1038/labinvest.2012.90; published online 28 May 2012

KEYWORDS: breast cancer therapy; COX-2; EP4 antagonist; lung metastasis; lymphangiogenesis; lymphatic metastasis; VEGF-C and -D

Cyclo-oxygenase (COX)-2, an inflammation-associated enzyme is believed to be a key factor during tumor initiation in tissues subjected to chronic inflammation. ${ }^{1}$ Furthermore, COX-2 overexpression is a signature as well as a major determinant of tumor progression and metastasis in a variety of cancers including breast cancer. ${ }^{1-3}$ In mice, transgenic overexpression of COX-2 induces mammary neoplasia, ${ }^{4}$ and its pharmacological inhibition ${ }^{5}$ or genetic deletion ${ }^{6}$ suppresses HER-2-induced mammary cancer development. COX-2 expression in human breast cancer is correlated with reduced survival, as well as other indicators of poor prognosis, such as increased tumor size, high tumor grade, negative hormone receptor status, HER-2 overexpression, ${ }^{7}$ angiogenesis, ${ }^{8}$ metastasis to lymph nodes ${ }^{8,9}$ and other organs. ${ }^{10}$ In a case-control study in women, use of selective COX-2 inhibitors was associated with a $71 \%$ reduction in breast cancer risk. ${ }^{11}$ Our laboratory had shown that tumor-derived PGE2 frequently resulting from elevated COX-2 expression promotes breast cancer progression by multiple mechanisms: an inactivation of host antitumor immune cells, ${ }^{12}$ a stimulation of tumor cell migration, invasiveness and tumor-associated angiogenesis ${ }^{13-16}$ as well as lymphangiogenesis resulting from an upregulation of

\footnotetext{
${ }^{1}$ Departments of Anatomy and Cell Biology, Schulich School of Medicine and Dentistry, University of Western Ontario, London, Ontario, Canada; ${ }^{2}$ Minase Research Institutes, Research Headquarters, Ono Pharmaceutical, Osaka, Japan and ${ }^{3}$ Department of Oncology, Schulich School of Medicine and Dentistry, University of Western Ontario, London, Ontario, Canada

Correspondence: Dr PK Lala, MD, PhD, Department of Anatomy and Cell Biology, University of Western Ontario, London, Ontario N6A5C1, Canada.

E-mail: pklala@uwo.ca

Received 29 February 2012; revised 28 March 2012; accepted 28 March 2012
} 
vascular endothelial growth factor (VEGF)-C, ${ }^{17}$ thereby promoting lymphatic metastasis. In these studies, COX-2-mediated promotion of migratory, ${ }^{15}$ invasive $^{16}$ and VEGF-C upregulatory ${ }^{17}$ functions were at least in part due to stimulation of PGE receptors prostaglandin E (EP)4, and to a minor extent EP1, expressed by breast cancer cells.

Whether lymphatic metastasis in human breast cancer occurs via pre-existing or newly formed lymphatics has been a subject of debate. ${ }^{18-20}$ However, recent evidence clearly reveals that expression of VEGF-C $C^{9,17,21}$ or VEGF-D ${ }^{22}$ in human breast cancer in situ is strongly correlated with lymphangiogenesis, lympho-vascular invasion and lymphatic metastasis. In addition to its role in promoting lymphangiogenesis, we found that VEGF-C production by breast cancer cells served as an autocrine stimulus for their motility by binding to a diverse group of VEGF-C receptors. ${ }^{23}$ Although VEGF-C production and lymphangiogenesis was a direct consequence of COX-2 expression in human breast cancer, ${ }^{17}$ we found that HER-2, often co-expressed with COX-2 in human breast cancer, had no direct role in VEGF-C upregulation or lymphangiogenesis, and that its role, if any, was COX-2 dependent. ${ }^{21}$

The facts that COX-2 is overexpressed in about half of breast cancer specimens ${ }^{7}$ inclusive of DCIS ${ }^{24}$ and invasive carcinomas, ${ }^{21}$ and has multiple roles in breast cancer progression and metastasis, make this molecule a reasonable therapeutic target. Recent safety concerns related to the cardiovascular side effects of high dose COX-2 inhibitors ${ }^{25,26}$ have led to the search for alternative targets downstream of COX-2, which would spare the vaso-protective prostacyclins. The PGE2 receptors (EP1, EP2, EP3 and EP4) may present as attractive alternatives because of their differential signaling abilities resulting from their coupling with different $G$ proteins. For example, EP1 is coupled with Gq, typically stimulating $\left[\mathrm{Ca}^{++}\right]_{\mathrm{i}} ; \mathrm{EP} 2$ and EP4 are coupled with Gs, stimulating adenylate cyclase (AC) followed by PKA activity; EP3 is typically coupled with $\mathrm{Gi}$, thus inhibiting AC, although some EP3 splice variants differ in their activity. ${ }^{27} \mathrm{EP} 4$, unlike EP2, can also activate an additional phosphatidylinositol 3-kinase (PI3K) pathway leading to AkT activation. ${ }^{28,29}$

Our observation that COX-2-mediated stimulation of VEGF-C and lymphangiogenesis in situ resulted largely from endogenous PGE2-mediated stimulation of EP4 and to a smaller extent EP1 receptors on human breast cancer cells, ${ }^{17}$ presented these receptors as candidate therapeutic targets against lymphatic metastasis. In view of the findings that suppression of host antitumor immune mechanisms may partially contribute to PGE2-mediated promotion of breast cancer progression, ${ }^{12,30-32}$ using human breast cancer xenografts in immuno-compromised mice was considered less than ideal for a preclinical testing of these targets. For this reason, this study was designed to develop a syngeneic COX-2 expressing murine breast cancer model of spontaneous lymphatic metastasis mimicking human and test it for therapy with COX-2 inhibitors and selective EP antagonists.
This model allowed us to conduct mechanistic studies in vitro and therapeutic as well as mechanistic studies in vivo, leading to the conclusion that EP4 is an excellent therapeutic target.

\section{MATERIALS AND METHODS Cell Lines}

C3L5 is a COX-2 expressing, PGE2 secreting murine breast cancer cell line produced in our laboratory, the PGE2 secreting ability primarily attributed to COX-2. ${ }^{14,16}$ It is a lung metastasis derivative of the $\mathrm{C} 3$ line, which was clonally derived from a spontaneous mammary adenocarcinoma in a $\mathrm{C} 3 \mathrm{H} / \mathrm{HeJ}$ retired breeder female mouse. ${ }^{12}$ Persistent metastatic ability of this clone was gained by five cycles of in vivo passage and selection of lung micro-metastases. ${ }^{33}$ Cells were maintained in high glucose DMEM (GIBCO, Grand Island, NY, USA) supplemented with 5\% fetal bovine serum, $100 \mathrm{U} /$ $\mathrm{ml}$ penicillin $\mathrm{G}$ and $100 \mu \mathrm{g} / \mathrm{ml}$ streptomycin in a humidified incubator with $5 \% \mathrm{CO}_{2}$ at $37^{\circ} \mathrm{C}$.

\section{Drugs}

Indomethacin (non-selective COX-1/COX-2 inhibitor, used for in vitro and in vivo studies) was obtained from Sigma (Oakville, ON, Canada). NS-398 (selective COX-2 inhibitor, used for in vitro studies) was from Cayman Chemical, Ann Arbor, MI, USA. AH 6809 (EP2 antagonist, used for in vitro studies) was from Biomol (Plymouth Meeting, PA, USA). Celecoxib (selective COX-2 inhibitor, used for in vitro and in vivo studies) was a gift of Pfizer, Groton, CT, USA. ONO8713, ONO-AE3-240 and ONO-AE3-208 (selective antagonists for EP1, EP3 and EP4, respectively, used for in vitro and in vivo studies) were generously provided by ONO Pharmaceuticals, Osaka, Japan. The structure, binding affinity, selectivity and pharmacokinetic properties of the EP antagonists have been characterized by ONO pharmaceuticals. ${ }^{34,35}$ For in vitro treatments, NS-398 and indomethacin were dissolved in $0.13 \%$ ethanol in PBS, and EP antagonists in $0.2 \%$ DMSO in PBS. For treating tumor transplanted mice, the details of all the vehicles used to dissolve or administer the drugs are presented later. For all treatments in vitro or in vivo, respective vehicles served as the control.

\section{Real-Time qPCR}

Total RNA from cells was extracted with the PerfectPure RNA Cultured Cell Kit (5 PRIME, Gaithersburg, MD, USA) and cDNA was synthesized with the qScript cDNA synthesis kit (Quanta Biosciences, Gaithersberg, MD, USA) in a T-Gradient thermocycler (Biometra GmbH, Gottingen, Germany). Quantitative RT-PCR (q-PCR) for VEGF-C, VEGF-D and GAPDH (housekeeping gene) was performed in triplicate using a Corbett Thermocycler (Corbett Research, Mortlake, Australia) and PerfeCTa SYBR green supermix (Quanta Biosciences). All primers were synthesized at the University of Western Ontario Oligo Factory as follows: VEGF-C primer sequence: $5^{\prime}$-GTATAGATGTGGGGAAGGAGT- $3^{\prime}$ (forward), 5'-GACACTGTGGTAATGTTGCTG-3' (reverse); VEGF-D 
primer sequence: $5^{\prime}$-GTAGCTGCCTGGAAACAACTG-3' (forward), 5'-GGTCCTCTGCCATTCTTCATC-3' (reverse); GAPDH primer sequence: $5^{\prime}$-GTAGCCGTATTCATTGTCAT$3^{\prime}$ (forward), 5'-AATGCATCCTGCACCACCAA-3' (reverse). Primers were checked for appropriate product size by PCR with murine cDNA. Fold changes in VEGF-C and VEGF-D mRNA following treatment of cells were expressed relative to GAPDH mRNA using delta Ct method.

\section{Knock Down of EP4 Receptor}

EP4 siRNA products consisted of pools of three to five targetspecific 19-25 nucleotide siRNAs designed to knockdown mouse EP4 gene expression (SC-40174, Santa Cruz Biotechnology, Santa Cruz, CA, USA) and silence select negative control siRNA (Cat. No: 4390843, Ambion) was used as EP4SC siRNA. Cells were incubated in a six-well cell culture plate, at a count of $5 \times 10^{4}$ cells per well. C3L5 cells were transfected with experimental and negative control siRNA (scrambled siRNA), respectively, in a separate well using JetPrime Polyplus DNA transfection reagent (Cat. No. 11407 ) using the DMEM medium with $10 \%$ FBS and incubated for $72 \mathrm{~h}$. C3L5 cells were washed with PBS and total RNA from respective treated cells was extracted with the PerfectPure RNA Cultured Cell Kit (5 PRIME) and cDNA was synthesized with the qScript cDNA synthesis kit (Quanta Biosciences). Transcript levels for GAPDH, VEGF-C and VEGF-D for each set of cDNA were quantified using respective primers as described above. EP4, VEGF-C and VEGF-D mRNA following treatment of cells were expressed relative to GAPDH using delta Ct method.

\section{Western Blot Analysis}

In all, $40 \mu \mathrm{g}$ total protein from cell lysates were run under reducing conditions on a SDS-PAGE gel (10\%) and transferred onto Immobilon PVDF membrane-FL (Millipore, Billerica, MA, USA). Polyclonal goat anti-mouse VEGF-C (1:200), rabbit anti-mouse VEGF-D (1:200) and monoclonal mouse anti-mouse $\beta$-actin (Santa Cruz Biotechnology) and polyclonal rabbit antibodies against EP1, EP2, EP3 or EP4 (1:200 dilution; Cayman Chemical) were used for immunoblotting, followed by incubation with IRDye polyclonal secondary antibodies from LI-COR (Lincoln, NE, USA): donkey anti-goat (1:5000), goat anti-rabbit (1:5000) and donkey anti-mouse (1:20000) as appropriate. Membranes were scanned on an Odyssey infrared imaging system (LICOR). For analysis of tumor tissues, samples were snapfrozen in liquid nitrogen and powdered with mortar and pestle before addition of lysis buffer. Samples were then homogenized with a polytron, and western blot was performed as described above for VEGF-C and VEGF-D and additionally total AkT and phospho-AkT (Thr-308) using rabbit polyclonal antibodies (1:1000) from Cell Signaling, Danvers, MA, USA.

\section{Enzyme-Linked Immunosorbent Assay (ELISA)}

Cells were serum starved for $48 \mathrm{~h}$ and supernatant centrifuged at $4500 \times g$ for $8 \mathrm{~min}$ to remove debris and ELISA for VEGF-C performed with the manufacturer's protocol (USCNLIFE Sciences and Technology, Wuhan, China). This could not be done for mouse VEGF-D because of unavailability of a suitable antibody or reproducible ELISA kit.

\section{Mice}

Six-week-old female $\mathrm{C} 3 \mathrm{H} / \mathrm{HeJ}$ mice were obtained from the Jackson Laboratory and allowed to acclimatize for 2-3 weeks, maintained on standard mouse chow and tap water (unless otherwise indicated) on a 12-h light-dark cycle, and treated in accordance with the guidelines set by the Canadian Council on Animal Care.

\section{Tumor Transplantation and Measurements of Tumor Progression}

Levels of tumor growth, tumor-associated angiogenesis and lymphangiogenesis were measured with an in vivo assay devised in our laboratory ${ }^{14,36}$ in which tumor cells suspended in growth factor-reduced Matrigel were implanted SC, allowing ingrowths of capillaries and lymphatics from pre-existing vasculature. Originally devised for measuring the kinetics of tumor-associated angiogenesis, ${ }^{36}$ our pilot studies revealed that this in vivo assay was also exquisitely suited for measuring tumor-associated lymphangiogenesis. Mice were randomized into treatment groups and received subcutaneous implants of $5 \times 10^{4} \mathrm{C} 3 \mathrm{~L} 5$ cells suspended in growth factorreduced Matrigel (3.5 mg Matrigel in $0.5 \mathrm{ml}$ DMEM) (BD Biosciences, Bedford, MA, USA) in both inguinal mammary regions. Some animals received implants of Matrigel alone, to serve as negative controls for angiogenesis or lymphangiogenesis. Treatment regimens included indomethacin $(12 \mu \mathrm{g} /$ $\mathrm{ml}$ drinking water), celecoxib $(125 \mathrm{mg} / \mathrm{kg}$ by oral gavage, b.i.d.), ONO-8713 and ONO AE3-208 (5 mg/kg by oral gavages, b.i.d.) or their vehicles alone (controls). Celecoxib was dissolved in $0.5 \%$ methylcellulose (Sigma). ONO-8713 and ONO-AE3-208 were dissolved in $0.003 \mathrm{~N} \mathrm{NaOH}$. The dosage and vehicles for using these drugs were guided by earlier reports for indomethacin, ${ }^{14}$ celecoxib $^{37}$ and EP antagonists. ${ }^{38}$ The water intake was measured daily to ensure that drug intake by the oral route did not affect their hydration compared with control mice receiving vehicles alone. Mice were killed by exposure to halothane followed by cervical dislocation, at 8,12 and 16 days $(n=8$ for each treatment with drugs or corresponding vehicle per day). On retrieval of the Matrigel implants (two per mouse), their weights and dimensions (maximum and minimum diameters) were recorded and gross morphology photographed. Tumors were then sliced in halves, each half fixed or frozen for further histological or immuno-histological analysis. Tumor-draining inguinal and distant axillary lymph nodes were removed and their dimensions measured before fixing them for histopathology. 


\section{Scoring Metastases}

Metastatic lung colonies were scored as previously reported, ${ }^{13}$ with a modification as follows. Lungs were inflated in situ with Bouin's fixative. Surface colonies on intact lungs being too small to be counted with a dissecting microscope at earlier time points, micro-metastases were scored in hematoxylin and eosin (H\&E)-stained coronal sections through mid-trachea (planned to obtain the maximal surface area of both lungs) in paraffin-embedded tissues. This provided a standardized method of scoring micro-metastases in both lungs. The micro-metastases were scanned and counted at $\times 100$ magnification, and verified at $\times 400$ magnification, under a Laborlux K microscope (Leitz, Germany). Mean and median scores of lung micro-metastases were based on eight mice per group, with each score acquired from counts of all lobes. Metastasis to lymph nodes were identified histologically in H\&E-stained sections of paraffin-embedded tissues, and scanned at $\times 100$ magnification and verified at higher $(\times 200$ and $\times 400)$ magnifications. Tumor-draining inguinal lymph nodes were assessed as sites of regional lymph node metastasis, and axillary nodes on each side (the first node receiving lymph drainage from the inguinal node) as sites of distant lymph node metastasis. As no specific marker was used for tumor cells, metastasis at the single cell level or as small cell clusters could not be accurately determined, until cancer cells appeared as overt colonies. Both pulmonary and lymphatic metastases were scored by two independent observers with $<7 \%$ variation and verified rigorously by one author (PKL), a trained histopathologist.

\section{Measurements of Angiogenesis and Lymphangiogenesis}

In all, $8 \mu \mathrm{m}$ thick frozen sections of Matrigel implants were fixed in methanol for $3 \mathrm{~min}$ and then in acetone for $3 \mathrm{~min}$, both at $4{ }^{\circ} \mathrm{C}$. All of the subsequent steps were performed at room temperature. Sections were air-dried for $1 \mathrm{~h}$, rehydrated for $10 \mathrm{~min}$ in PBS, followed by treatment with $2 \%$ BSA in PBS for 20 min to block nonspecific antibody binding. Sections were then incubated for $1 \mathrm{~h}$ with rabbit anti-mouse LYVE-1 (Upstate Biotechnologies, Lake Placid, NY, USA; 1:200) and rat anti-mouse CD31 (Caltag Laboratories, Advanced Medical Sciences, Bangkok, Thailand, 1:1000) antibodies, followed by normal mouse serum (1\%) for $10 \mathrm{~min}$ to block nonspecific cross-reactivity of secondary antibodies with mouse proteins. Sections were then incubated for 30 min with goat anti-rabbit Alexa Fluor 488 and donkey anti-rat Alexa Fluor 594 secondary antibodies (Molecular Probes, Burlington, ON, Canada; 1:1000, washed with PBS, drained, and mounted with Vectashield solution (Vector Laboratories, Burlington, ON, Canada). The sections from all tumors were first scanned at low magnification $(\times 250)$ under a BX51 microscope (Olympus) to identify the most vascular areas of the tumor. Adjacent sections of fixed tissues stained with Masson's Trichrome ${ }^{36}$ visualized under bright field microscopy provided a map to locate vessels within the peritumoral stroma as well as within the tumors. With this method, capillaries devoid of red cells could not be adequately discriminated between blood or lymphatic capillaries. Microvessel density (MVD) representing blood vessels and lymphatic vessel density (LVD) were assessed in dual immunostained sections of frozen tissues as reported, ${ }^{36,39}$ with the following modification. Three hotspots per tumor ( 48 per group per day) were examined at $\times 400$ magnification, and scored after setting the threshold for background, using the Image-J software (NIH, USA). The mean values for MVD and LVD were computed as the staining indices for CD31 (red) and LYVE-1 (green), respectively.

\section{Computing Apoptotic/Proliferative Cell Ratios}

Serial $8 \mu \mathrm{m}$ thick deparaffinized histological sections of paraffin-embedded tumor tissues from vehicle-treated and drugtreated mice were immunostained for proliferative cell marker Ki67 (monoclonal rat anti-mouse antibody from Dako Canada, Burlington, ON, Canada, applied at 1:200 dilution in PBS-BSA overnight at $4{ }^{\circ} \mathrm{C}$ ) and apoptotic cells by dUTP nick end labeling (TUNEL apoptosis detection kit and protocol from Trevigen, Gaithersburg, MD, USA) after proteinase $\mathrm{K}$ antigen retrieval. Ki67 was detected with biotinlabeled secondary antibody treatment (1:2000), followed by Streptavidin-Texas red (red fluorescence). TUNEL staining gave green fluorescence. The ratios of apoptotic/proliferative cells were determined by image analysis (Image-J program).

\section{Statistical Analysis}

Data were analyzed using the Sigma Stat (version 3.5, Systat, San Jose, CA, USA) program employing two-way ANOVA and tested by Student's $t$-test, with one exception. To compare lung micro-metastases between control (vehicle-treated) and drug-treated mice, the data were also subjected to the non-parametric Wilcoxon rank sum test. A $P$-value of $<0.05$ was considered as significant.

\section{RESULTS \\ COX-2 Inhibitors and EP4 Antagonist reduce VEGF-C and VEGF-D Production by C3L5 Cells}

C3L5 cells expressed high levels of COX-2 (Figure 1a) and released PGE2 in serum-free media, and this release was blocked equally by treating cells $(48 \mathrm{~h})$ with COX-1/COX-2 inhibitor indomethacin $(20 \mu \mathrm{M})$, COX-2 inhibitors NS-398 $(20 \mu \mathrm{M})$ or celecoxib $(1-10 \mu \mathrm{M})$, confirming our earlier findings ${ }^{14,16}$ that COX-2 is the primary enzyme responsible for PGE2 production by the cells (data not shown). VEGF-C and VEGF-D mRNA and proteins, as detected by qPCR (Figure 1b) and western blotting (Figure 1f) and secreted VEGF-C by ELISA (control in Figures 1d and e). C3L 5 cells were cultured for $48 \mathrm{~h}$ with indomethacin $(20 \mu \mathrm{M})$, NS-398 $(20 \mu \mathrm{M})$, celecoxib $(1 \mu \mathrm{M})$, a selective EP1 antagonist (EP1A) ONO-8713 $(2 \mu \mathrm{M})$; non-selective EP2 antagonist (EP2A) AH $6809(2 \mu \mathrm{M})$; a selective EP3 antagonist (EP3A) ONO-AE3$240(2 \mu \mathrm{M})$; a selective EP4 antagonist (EP4A) ONO-AE3$208(2 \mu \mathrm{M})$. Treating cells with indomethacin $(20 \mu \mathrm{M})$, or 
a
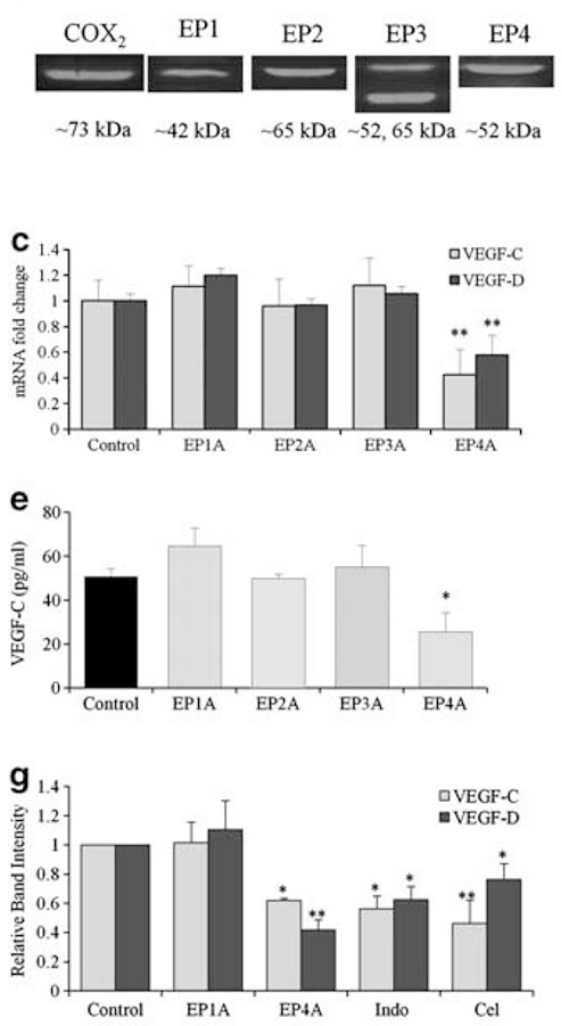

b

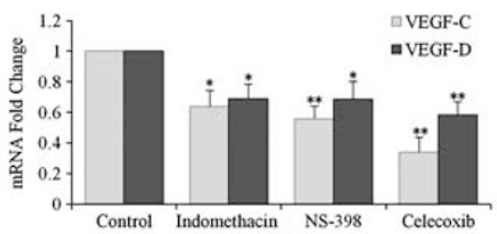

d

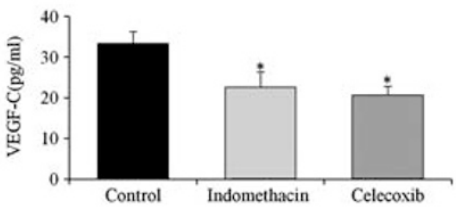

f

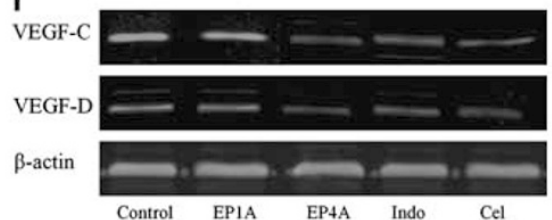

h

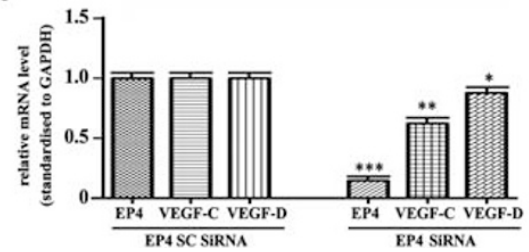

Figure 1 COX-1/2 and COX-2 inhibitors and EP4 antagonist reduce VEGF-C and VEGF-D production in C3L5 cells. (a) Western blot analysis of proteins in C3I5 cell lysates revealed expression of COX-2 and all the EP receptors. (b, c) Both COX1/2 and COX-2 inhibitors as well as the EP4 (but not EP1, EP2 and EP3) antagonist suppressed VEGF-C and -D mRNA levels relative to GAPDH mRNA (presented as a fraction of control vehicle-treated cells) as well as secreted VEGF-C (d, e) measured with ELISA. C3L5 cells express VEGF-C ( $80 \mathrm{kDa})$ and VEGF-D (21 kDa) (f, control) measured with western blot, which were reduced by treatments with COX inhibitors and EP4 (but not EP1) antagonist, as compared with vehicle-treated control cells (f, g). siRNA-mediated knockdown of EP4 resulted in significant drop in VEGF-C and VEGF-D mRNA (h). Data presented in (a, b), (c, d) and (e, f) are from three different representative experiments. Data represent means $(n=4) \pm$ s.e., ${ }^{\star} P<0.05,{ }^{*} p<0.01,{ }^{* *} p<0.001$.

NS-398 $(20 \mu \mathrm{M})$ or celecoxib $(1 \mu \mathrm{M})$ for $48 \mathrm{~h}$ suppressed VEGF-C and VEGF-D mRNA expression (Figure 1b). Similarly, indomethacin and celecoxib treatments suppressed VEGF-C secretion (Figure 1d), measured with ELISA of the cell-free supernatants.

\section{EP4 but not other EP Receptors Contribute to VEGF-C and VEGF-D Production by C3L5 Cells}

Figure 1a shows that C3L5 cells express all the EP receptor (EP1, EP2, EP3 and EP4) proteins as detected by western blotting. Figure 1c shows that the EP4 antagonist ONO-AE3208, but none of the other EP antagonists, significantly suppressed the VEGF-C and VEGF-D mRNA expression. Similarly, as shown in Figure 1e, secreted VEGF-C accumulation in supernatants of C3L 5 cells grown for $48 \mathrm{~h}$ in serumfree medium was significantly inhibited by treating cells with the EP4 antagonist, but not EP1, EP2 or EP3 antagonists, as compared with vehicle (DMSO) treatment alone. Furthermore, treatments with COX inhibitors as well as EP4 but not other EP antagonists reduced both VEGF-C and VEGF-D protein levels in C3L5 cell lysates (Figures if and g). These findings of the differential role of EP4 activity in VEGF-C and VEGF-D upregulation was validated further by siRNAmediated knockdown ( $115 \mathrm{nM}$ of siRNA) of EP4 mRNA in C3L5 cells (Figure 1h). The efficiency of the knock down was 80-85\%. VEGF-C and VEGF-D mRNA levels in C3L5 cells were significantly downregulated by EP4-specific siRNA treatment as compared with scrambled (control) siRNA treatment (Figure 1h) or no treatment (indistinguishable from the former; data not shown).

\section{Therapy with Non-Selective or Selective COX-2 Inhibitors or EP4 Antagonist Inhibits the Growth of Primary C3L5 Tumors in Syngeneic Mice}

Implants of Matrigel alone in a small number (six) of control mice remained unchanged in size appearing as clear avascular jelly beans (Figure $2 \mathrm{~b}$ ). The growth of the primary tumors resulting from tumor cell-inclusive Matrigel implants was measured by two different methods giving similar results. The tumor volumes (computed as $0.5 \times \mathrm{a}^{2} \mathrm{~b}$, from the minimum (a) and maximum (b) diameters of the retrieved tumors, data not shown) as well as the weights of fresh 

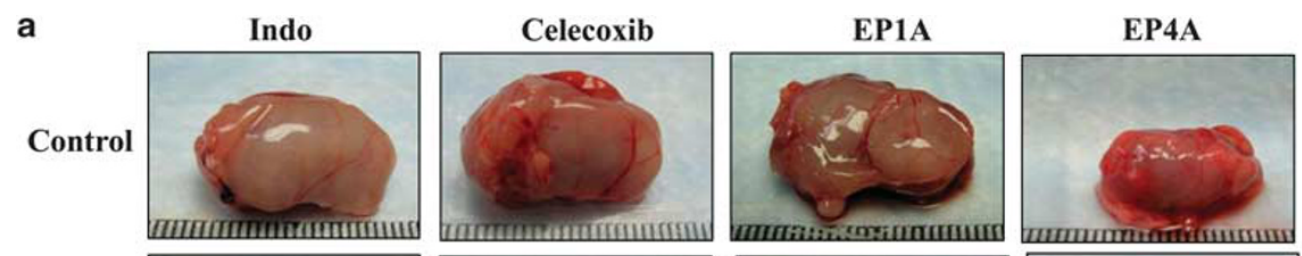

b
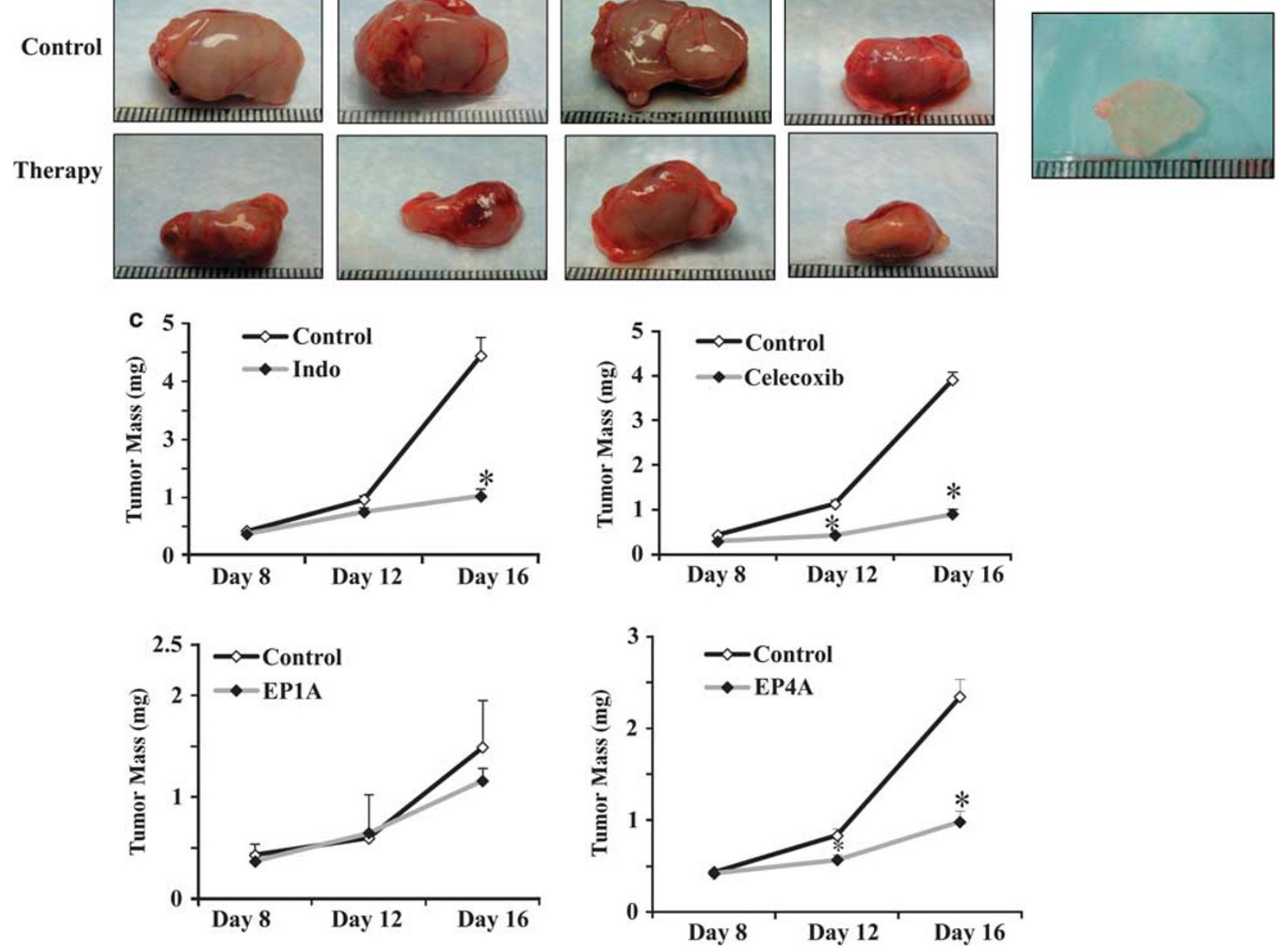

Figure 2 Therapy with COX-1/2 and COX-2 inhibitors or EP4 antagonist, but not EP1 antagonist reduces primary tumor growth in C3H/HeJ mice. (a) Representative images of tumor-inclusive Matrigel implants retrieved on day 16 (a scale in $\mathrm{mm}$ shown in the background). (b) Image of only Matrigel implant retrieved on day 16. (c) Mean weights of tumors were reduced significantly in mice treated with indomethacin, celecoxib or EP4 antagonist ONOAE3-208 (EP4A), but not EP1 antagonist ONO-8713 (EP1A), compared with respective vehicle-treated controls. This reduction was significant day 12 with celecoxib and EP4A, and highly significant on day 16 for all therapies except EP1A. Data represent mean $\left(n=16\right.$ per group per day \pm \pm s.e. ${ }^{\star P}<0.05$, $* * P<0.005$.

unfixed tumors (data shown in Figure 2c, along with gross morphology of representative tumors in Figure 2a) were significantly reduced by all therapies except with EP1 antagonist. This reduction was significant at day $12(P<0.05)$ for celecoxib and EP4A treatments and highly significant $(P<0.005)$ on day 16 for indomethacin, celecoxib and EP4A treatments, as compared with respective control vehicle treatments. EP1 antagonist ONO-8713 caused no significant reduction at any time. None of these drugs had any effect on the daily water intake (data not shown) excluding any confounding effects of water deprivation. None of the mice at autopsy (days 8, 12 and 16) exhibited any gastro-intestinal bleeding indicative of treatment-related toxicity. These data were highly reproducible in two other pilot experiments, which had to be terminated on days $18-20$, when control tumor-bearing mice developed tumor-related stress. The combined data revealed that significant reduction in tumor growth occurred on days 11-12 and continued until day 20 with indomethacin, celecoxib and EP4A.

\section{Therapy with Non-Selective or Selective COX-2} Inhibitors or EP4 Antagonist Reduced Tumor-Associated Angiogenesis and Lymphangiogenesis in $\mathrm{C} 3 \mathrm{H} / \mathrm{HeJ}$ Mice No measurable angiogenesis or lymphangiogenesis was observed in tumor cell-exclusive Matrigel implants at any interval (not shown) confirming our earlier findings on angiogenesis. ${ }^{36}$ We additionally found that growth factorreduced Matrigel, on its own, did not stimulate lymphangiogenesis. In Figure 3a, bright field images of Masson's Trichrome-stained sections, adjacent to fluorescence microscopy images, are included to show that blood vessels were most abundant in the peritumoral stroma. The immuno- 
a
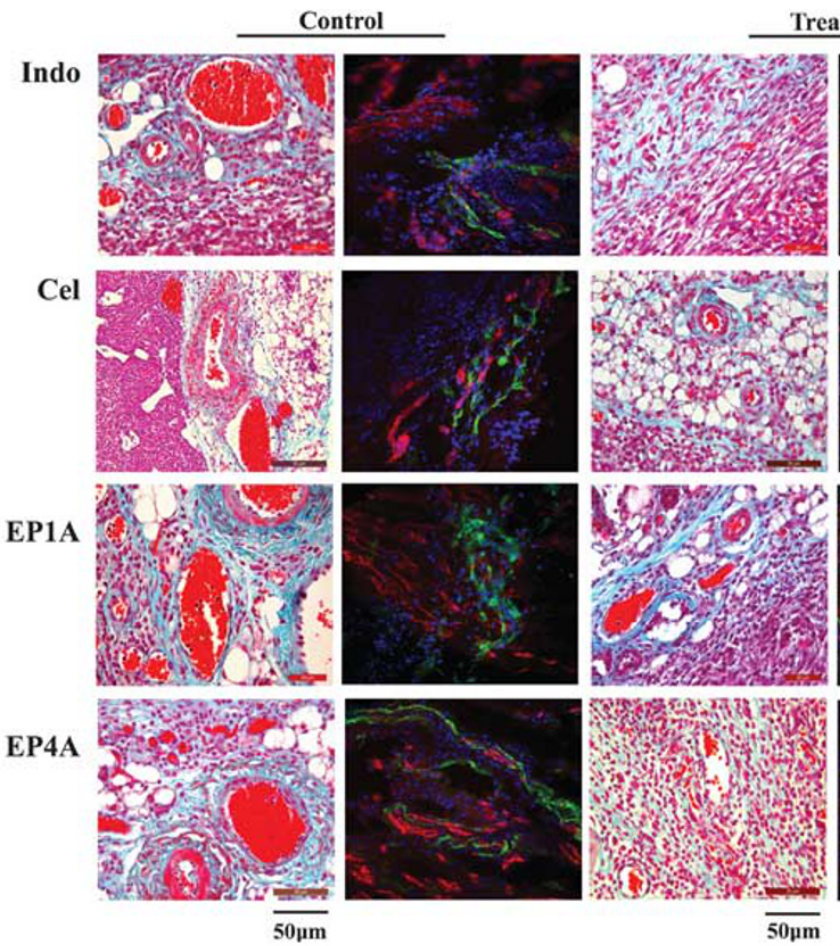

Treated

b

Indomethacin Treatment
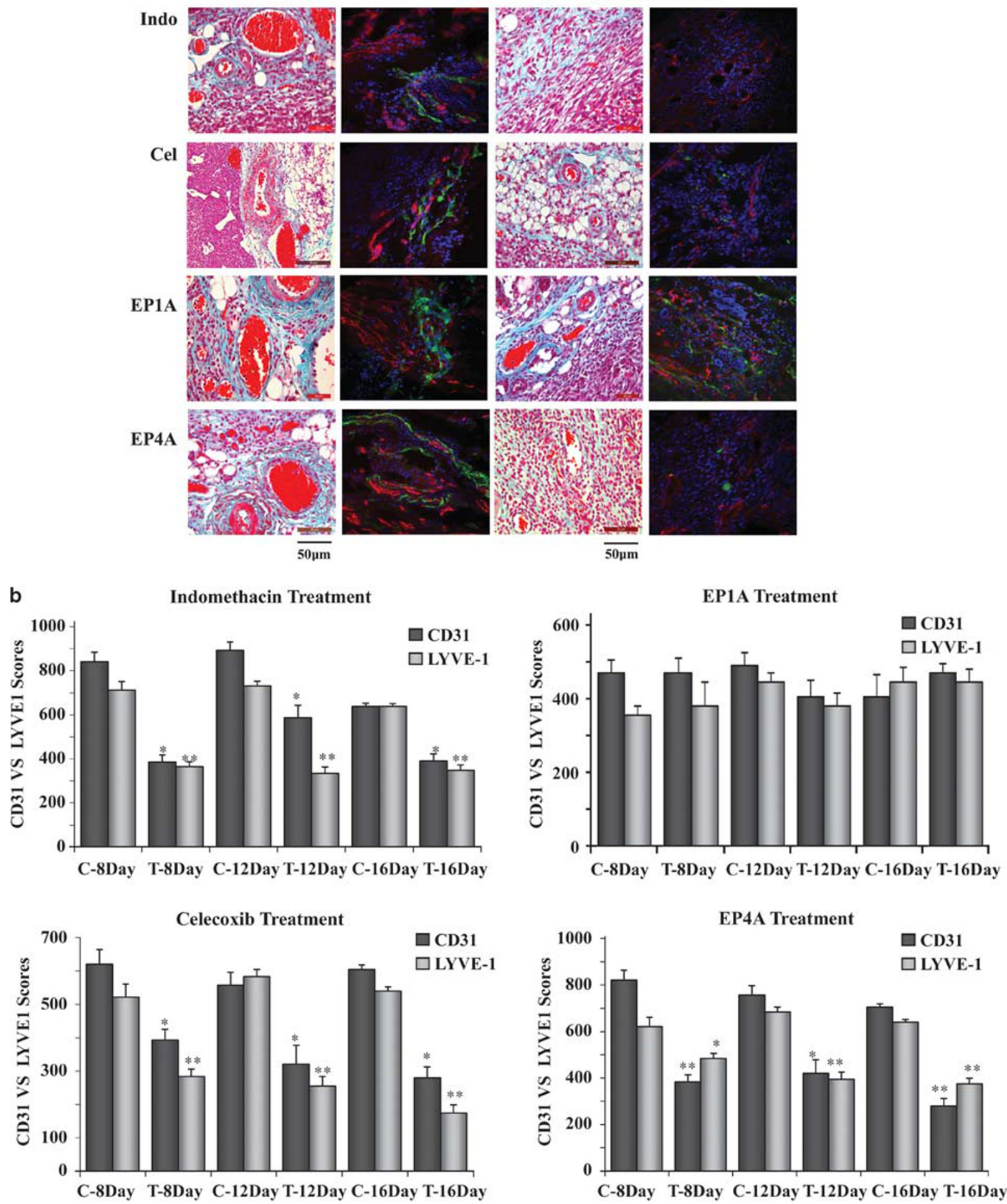

Figure 3 Therapy with non-selective or selective COX-2 inhibitors or EP4 antagonist reduced tumor-associated angiogenesis and lymphangiogenesis in $\mathrm{C} 3 \mathrm{H} / \mathrm{HeJ}$ mice. (a) Bright field images of Masson's Tricrome-stained sections (first and third columns) showing peritumoral stroma inclusive of vessels (scale bars in $\mu \mathrm{m}$ given as insets), and fluorescence images of corresponding tumors representing 'hot spots' within the tumors (second and fourth columns). Tumor-associated angiogenesis (CD31 immuno-staining in red) and lymphangiogenesis (LYVE-1 immuno-staining in green), are shown as representative fluorescent merged images. There was practically no overlap between the vessels identified by two colors confirming the specificity of the markers. Therapy with COX-1/2 and COX-2 inhibitors or EP4 antagonist but not EP1 antagonist significantly reduced both angiogenesis and lymphangiogenesis. Representative images are shown in (a) and quantified as corresponding 'hot spot' scores for CD31 and LYVE-1 (b) ( $n=16$, using the mean of three hot spots from each of the 16 tumors per group) \pm s.e., ${ }^{\star} P<0.05$, ${ }^{* *} P<0.005$. 
fluorescence images are representative of 'hot spots' within the tumors. High levels of tumor-associated angiogenesis as well as lymphangiogenesis (identified respectively with CD31 and LYVE-1 immunostaining, shown in merged pictures in Figure 3a, and quantified in Figure 3b) occurred in all vehicle-treated mice at all-time points with very little or no temporal change. A significant reduction of both events occurred at all-time points with all the therapies except with the EP1 antagonist. These drug effects (Figure 3) appeared to precede their growth inhibitory effects on tumor mass (Figure 2c). For example, reduction in angiogenesis and lymphangiogenesis were noted on day 8 , whereas a reduction in tumor mass was first noted on days 11 and 12 of therapy.

\section{Therapies with Non-Selective or Selective COX-2 Inhibitor or EP4 Antagonist Inhibit Regional and Distant Lymph Node Metastases}

As EP1 antagonist was ineffective in reducing tumor growth or tumor-associated lymphangiogenesis, we refrained from a laborious histopathological analysis of lymphatic metastasis in this group. Table 1 summarizes the incidence of lymph nodes exhibiting histological evidence of metastasis in all other vehicle- and drug-treated groups.

On pooling the data from all vehicle-treated control mice, the incidence of tumor-positive inguinal nodes showed an increase from $44 \%$ on day 8 to $85 \%$ and $69 \%$, respectively, on days 12 and 16. For the axillary nodes, this incidence was $29-38 \%$ on days 8 and 12 , increasing to $50 \%$ on day 16 . All therapies (indomethacin, celecoxib and ONO-AE3-208) drastically reduced this incidence on day 12 , bringing it down to $0 \%$ on day 16. A significant reduction was evident on day 8, with EP4A. As metastasis at the single cell or small cell cluster level was not identifiable reliably on histological grounds, and many putative lymph nodes showing only tumor cells and no lymph node architecture were excluded from the analysis, the above incidence can be considered as minimal in all groups. Figure 4 shows representative histological pictures in H\&E-stained sections of some of the nodes.

\section{Therapy with COX-1/2 Inhibitor, COX-2 Inhibitor or EP4 Antagonist Reduces Spontaneous Lung Metastasis}

Micro-metastases in H\&E-stained lung sections were noted as early as day 8 in control mice (image not presented, quantification in Figure 5b). Representative images of lung sections recorded at day 16 are shown in Figure 5a. Figure 5b shows the median number of metastatic lung colonies at various times after tumor transplantation. Therapies with indomethacin, celecoxib and ONO-AE3-208 all significantly abrogated lung micro-metastases. In contrast, EP1 antagonist ONO- 8713 did not have any anti-metastatic effect. In fact, it slightly (but not significantly, $P=0.056$ ) promoted metastases scored on day 12 .
Table 1 Incidence of tumor-positive lymph nodes in different groups

\begin{tabular}{|c|c|c|c|c|c|}
\hline & & & $\begin{array}{c}\text { Day } 8 \\
n / N^{\mathrm{a}}(\%)\end{array}$ & $\begin{array}{c}\text { Day } 12 \\
n / N^{\mathrm{a}}(\%)\end{array}$ & $\begin{array}{l}\text { Day } 16 \\
n / N^{\mathrm{a}}(\%)\end{array}$ \\
\hline \multirow[t]{6}{*}{ Inguinal } & Indomethacin & Control & $2 / 4(50)$ & $4 / 4(100)$ & $3 / 5(60)$ \\
\hline & & Treatment & $3 / 8(37.5)$ & $1 / 5(20)$ & $0 / 3(0)$ \\
\hline & Celecoxib & Control & $3 / 7(42.9)$ & $5 / 6(83.3)$ & $4 / 5(80)$ \\
\hline & & Treatment & 2/6 (33.3) & $1 / 7(14.3)$ & $0 / 6(0)$ \\
\hline & EP4A & Control & $3 / 7(42.9)$ & $3 / 4(75)$ & $2 / 3(66.7)$ \\
\hline & & Treatment & $1 / 4(25)$ & $0 / 4(0)$ & $0 / 4(0)$ \\
\hline \multirow[t]{6}{*}{ Axillary } & Indomethacin & Control & $3 / 9(33.3)$ & $2 / 8(25)$ & $3 / 4(75)$ \\
\hline & & Treatment & $1 / 10(10)$ & $0 / 7(0)$ & $0 / 4(0)$ \\
\hline & Celecoxib & Control & 3/9 (33.3) & 2/7 (28.6) & $4 / 8(50)$ \\
\hline & & Treatment & $0 / 10(0)$ & $0 / 7(0)$ & $0 / 8(0)$ \\
\hline & EP4A & Control & 4/13 (30.8) & $1 / 3(33.3)$ & $4 / 10(40)$ \\
\hline & & Treatment & $0 / 10(0)$ & $1 / 6(16.7)$ & $0 / 8(0)$ \\
\hline
\end{tabular}

a Tumor-positive (n)/total $(N)$; many putative lymph nodes identified at the gross level had no histological architecture of lymph nodes and were indistinguishable from tumor tissue. These nodes were excluded from the analysis. Control $=$ respective vehicle-treated mice.

\section{Therapy with COX-1/2 Inhibitor, COX-2 Inhibitor or EP4 Antagonist Reduces the Levels of VEGF-C and VEGF-D Proteins and Phosphorylated AkT in Residual Tumors, Concomitant with an Increase in Apoptotic/Proliferative Cell Ratios}

Our in vitro data revealed that the production of the lymphangiogenic factors VEGF-C and VEGF-D by tumor cells was inhibited with indomethacin, celecoxib and as well as ONO-AE3-208. As these drugs also reduced tumor growth and tumor-associated lymphangiogenesis in vivo, we tested whether there was a concomitant reduction in the levels of VEGF-C and VEGF-D proteins within the residual tumors with these therapies. Western blot data in Figure 6 shows that this was indeed the case. Although an activation of both EP2 and EP4 receptors stimulate the cAMP pathway, EP4 activation also stimulates PI3K/AkT pathway to promote tumor growth/survival. ${ }^{29,40}$ For this reason, we tested whether the cyto-reductive effects of indomethacin, celecoxib and EP4 antagonist therapies, were all associated with reduction of EP4 activity and thereby a reduction of AkT phosphorylation in the tumors. Western blot data in Figure 6 and apoptotic/ proliferative cell ratios in Figure 7 confirm this contention. These ratios were significantly higher in EP4A-treated mice as compared with vehicle-treated mice at all-time points. Furthermore, there was a significant temporal increase in this ratio in EP4A-treated mice, whereas there was a significant temporal decline in control mice. Data (not presented) were very similar for indomethacin and celecoxib-treated mice. 

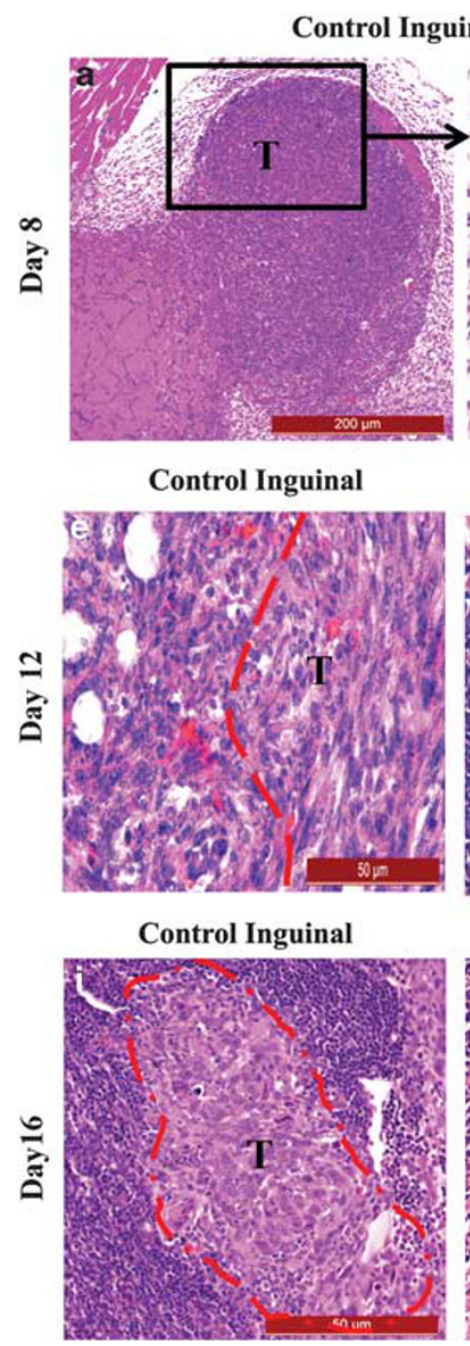
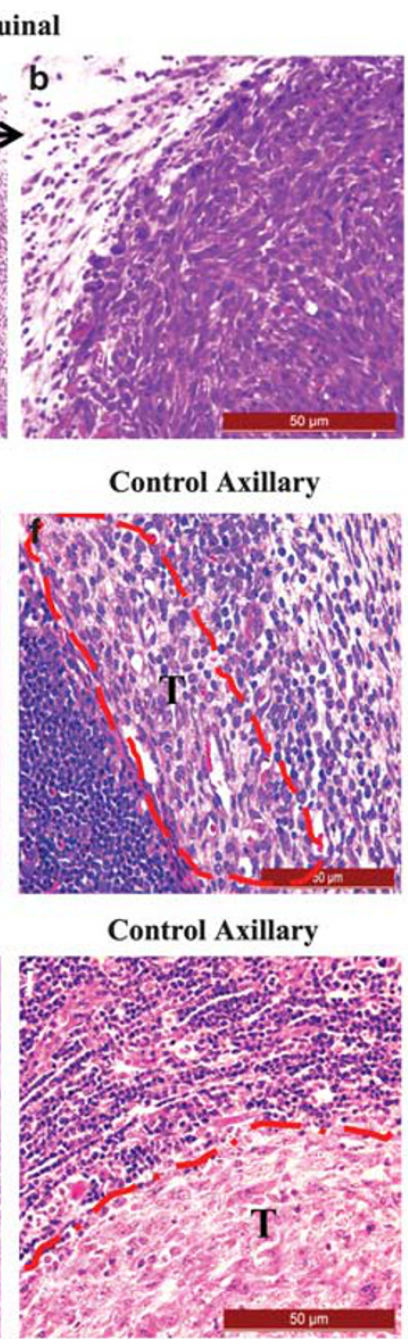

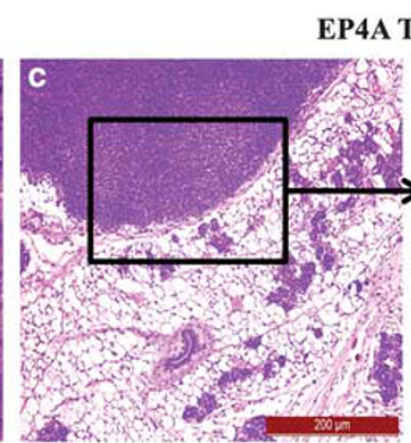

Cel Treated Axillary
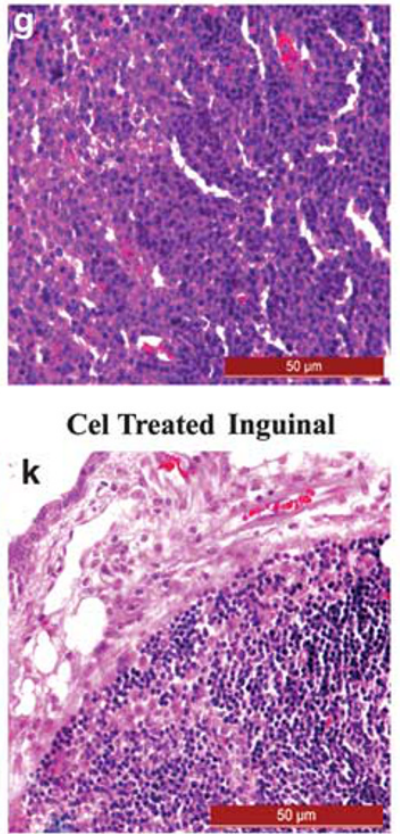

EP4A Treated Inguinal

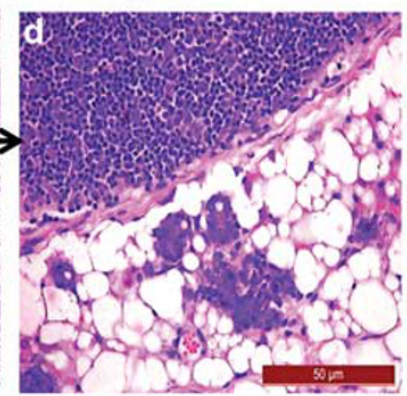

EP4A Treated Inguinal
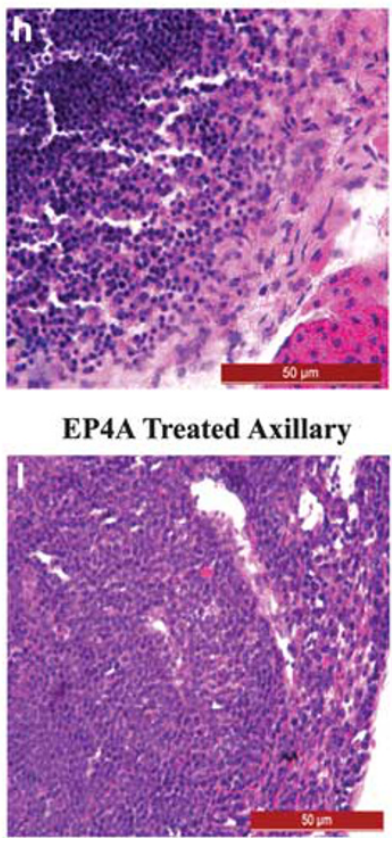

Figure 4 Therapy with COX-1/2 inhibitor or COX-2 inhibitor or EP4 antagonist abrogated regional and distant lymph node metastasis. Histological pictures (H\&E stained) of representative lymph nodes: Day 8: inguinal nodes in control (vehicle treated) (a, inset magnified fourfold in (b) and EP4A treated (c), inset magnified fourfold in d) mice. Lymph node in (a) is completely replaced by tumor cells (marked as T) showing the trail of invasion from the primary tumor on the left. Lymph node in (c) is tumor free. Day 12: nodes in (e, f) show metastatic tumor cells (T), outlined by red markings; lymph nodes in $(\mathbf{g}, \mathbf{h})$ are tumor-free. Day 16: nodes in $(\mathbf{i}, \mathbf{j})$ show tumor cells $(T)$, outlined by red markings. Nodes in ( $\mathbf{k}, \mathbf{I})$ are tumor free. Scale bars for magnification in images are shown as insets ( $50 \mu \mathrm{m}$ for all, except for $\mathbf{a}$ and $\mathbf{c}, 200 \mu \mathrm{m})$.

\section{DISCUSSION}

Present in vitro studies revealed that high COX-2 expressing C3L5 breast cancer cells express all the EP receptors and produce VEGF-C and VEGF-D, both of which could be downregulated with COX-1/COX-2 or COX-2 inhibitors and an EP4 antagonist, similar to our findings in COX-2 expressing, VEGF-C producing human breast cancer cell lines. ${ }^{17}$ The role of EP4 was further validated with siRNAmediated knockdown. We confirmed our earlier findings that subcutaneous transplants of C3L5 cells suspended in growth factor-reduced Matrigel in both inguinal regions of $\mathrm{C} 3 \mathrm{H} / \mathrm{HeJ}$ mice provided a robust system for measuring tumor-associated angiogenesis. ${ }^{36}$ Additionally, we show that system is also exquisitely suited to measuring tumor-associated lymphangiogenesis and lymphatic metastasis to local and distant nodes. Although human cancer cell xenografts in immunodeficient mice have been utilized to study tumor-associated lymphangiogenesis and/or lymphatic metastasis, ${ }^{41,42}$ to our knowledge, ours is the first syngeneic breast cancer model in immune competent mice showing rapid and spontaneous metastasis of the primary tumor to regional and distant lymph nodes, mimicking aggressive breast cancer in the human. Using this model, this study demonstrated that an EP4 antagonist ONO-AE3-208, but not EP1 antagonist ONO8713 was highly and equally effective as a COX-2 inhibitor celecoxib in inhibiting primary tumor growth, tumor-associated angiogenesis and lymphangiogenesis, and metastasis to the lymph nodes and the lungs. In view of the fact that the tumor burden was very high because of the dual transplants in our present tumor model, the observed therapeutic effects 
a

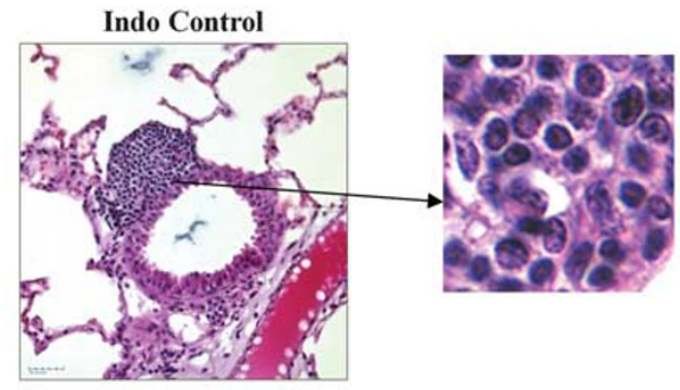

Cel Control
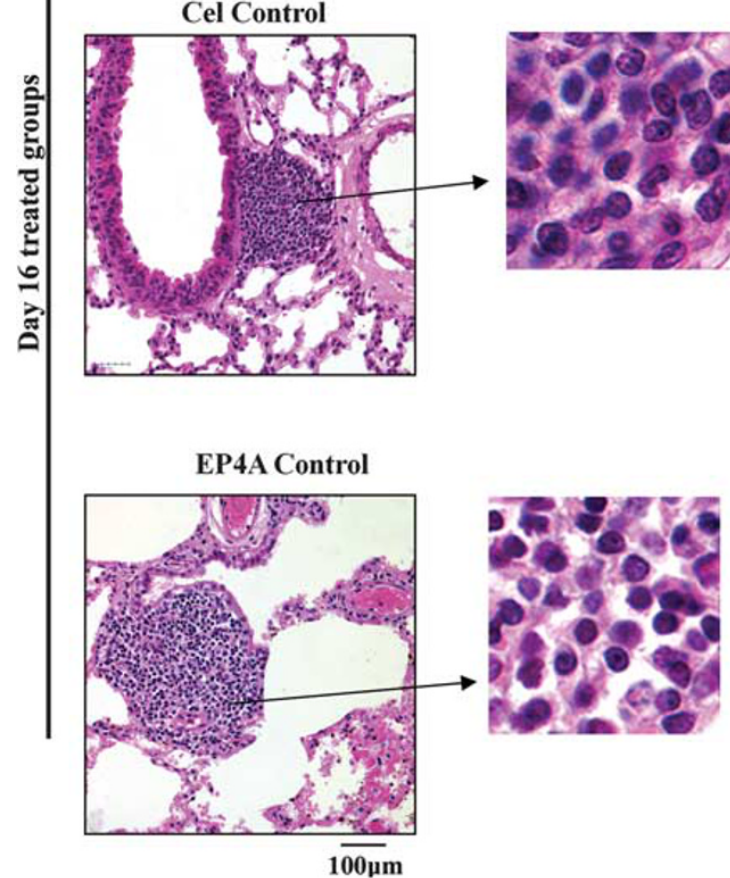

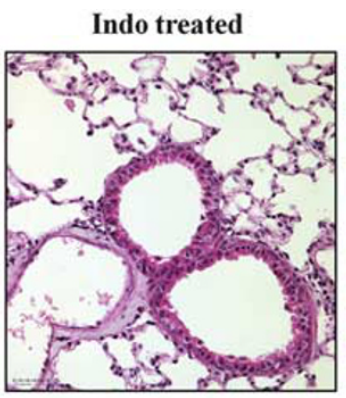

Cel Treated
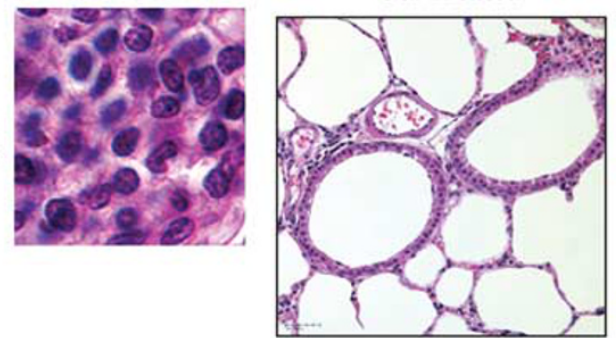

EP4A Treated

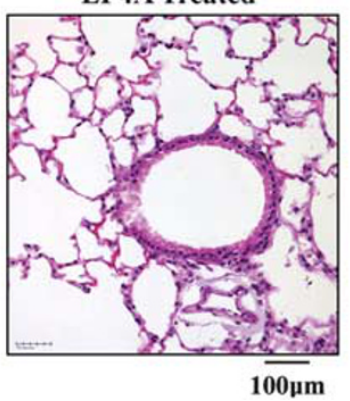

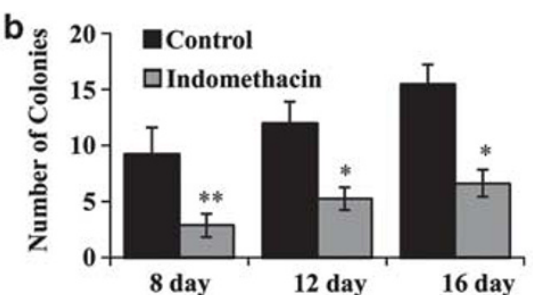
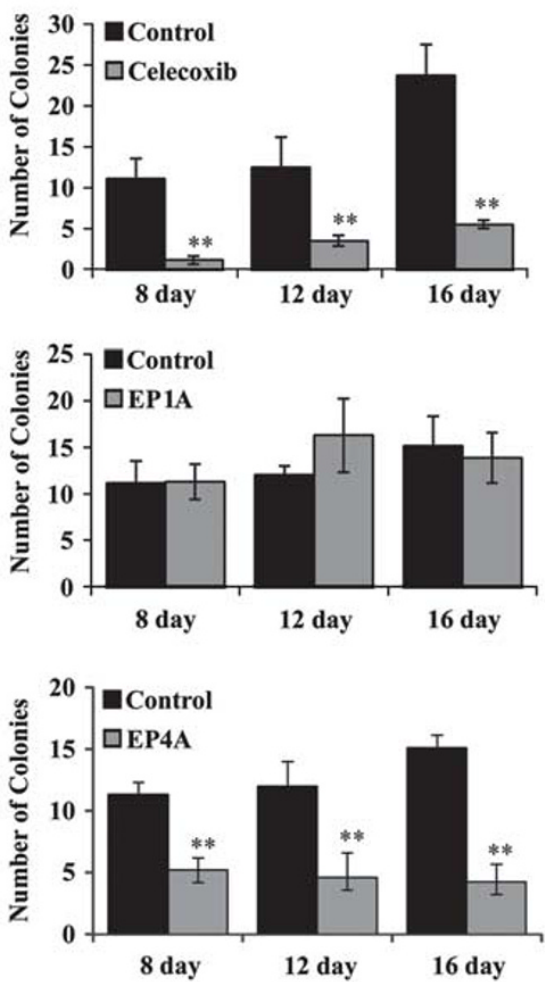

Figure 5 Therapy with COX-1/2 and COX-2 inhibitors or EP4 antagonist reduces metastatic lung colony formation. (a) Representative images of micro metastases in H\&E-stained lung sections on day 16. They were noted as early as day 8 (data not presented). Scale bar represents $100 \mu \mathrm{m}$. (b) Median numbers of metastatic lung colonies were reduced with all treatments (except EP1A) at all-time points after tumor transplantation. ( $n=8$ per group per day). Data represent median \pm quartile deviations. ${ }^{*} P<0.05 ;{ }^{*} P<0.01$.

may possibly be under-estimated in comparison with our single transplant model used to measure effects of the NOS inhibitor L-NAME ${ }^{36}$ and the COX inhibitor indomethacin ${ }^{14}$ on tumor-associated angiogenesis.

VEGF-C, a key promoter of lymphangiogenesis, was shown to be upregulated by COX-2 in human breast cancer, ${ }^{17}$ as also replicated in our present murine model. Although the role of VEGF-D in breast cancer-associated lymphangiogenesis and lymphatic metastasis has been documented, ${ }^{22}$ to our knowledge this is the first study to report the role of COX-2 in upregulating VEGF-D in breast cancer.

The roles of individual EP receptors in tumor development and progression have so far been shown to vary with the tumor model and the specific cellular functions contributing to the cancer progression. Multiple EP receptors have been implicated in various aspects of breast cancer development and progression: EP1 in mammary carcinogenesis; ${ }^{43} \mathrm{EP} 2$ in
COX-2-induced mammary hyperplasia; ${ }^{44}$ EP4 in promoting invasiveness in an inflammatory type breast cancer cell line. ${ }^{45}$ We have reported earlier that EP4, and to a smaller extent EP1 was responsible for both migration-stimulatory ${ }^{15}$ and VEGF-C upregulatory ${ }^{17}$ actions of endogenous PGE2 on breast cancer cells. In addition to confirming the role of EP4 in VEGF-C production, this study also revealed its role in VEGF-D upregulation, consistent with the report that an EP4 agonist upregulated VEGF-D in cultured fibroblast cells. ${ }^{46}$ Taken together, EP4 appears to have a major role in COX-2 actions in breast cancer progression, making it a logical therapeutic target for intervening breast cancer-associated lymphangiogenesis and lymphatic metastasis, as validated in this study. In spite of our earlier findings of participation of EP1 in breast cancer cell migration ${ }^{15}$ and VEGF-C upregulation, ${ }^{17}$ the presently used EP1 antagonist proved to be ineffective in vivo in our murine breast cancer model. 


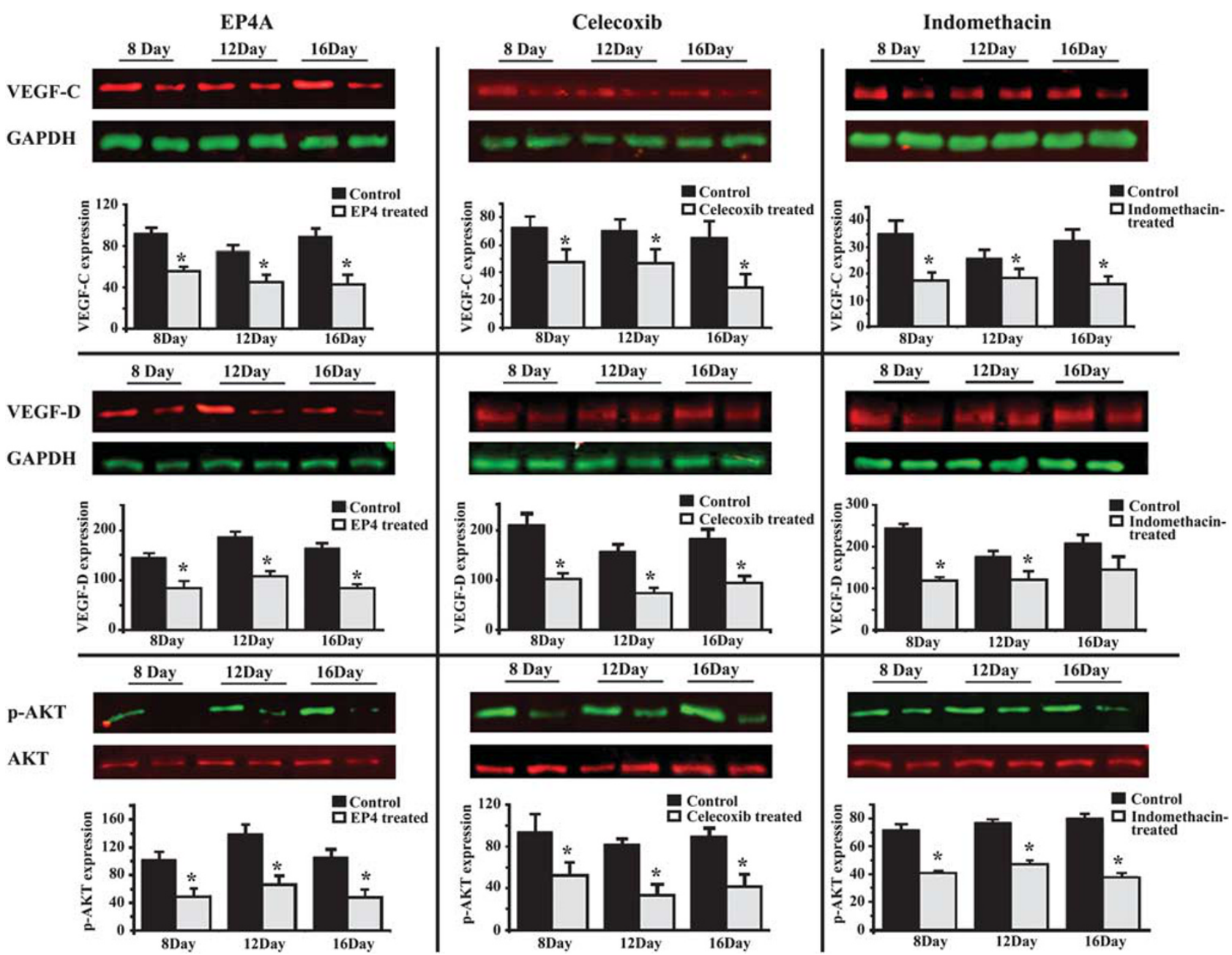

Figure 6 Therapy with COX-1/2 inhibitor, COX-2 inhibitor and EP4 antagonist reduces the levels of VEGF-C, -D and phosphorylated AkT proteins in residual tumors. Total tumor lysate proteins (pooled from eight tumors per group, triplicate measurements) were subjected to western blots for pAkT and total AkT, VEGF-C and -D and GAPDH proteins. Densitometric measurements of pAkT relative to total AkT, and VEGF-C and -D relative to GAPDH reveal a significant reduction of all these parameters in the drug-treated groups at all intervals, as compared with vehicle-treated controls. Data represent mean \pm s.e., ${ }^{*} P<0.05$.

This is the first study to demonstrate therapeutic efficacy of a COX-2 inhibitor or an EP4 antagonist, but not EP1 antagonist in vivo in inhibiting breast cancer-associated lymphangiogenesis and lymphatic metastasis. In earlier reports, pharmacological antagonism of $\mathrm{EP}^{47}$ or $\mathrm{EP}^{48}$ by in vitro treatment of murine breast cancer cell lines with respective EP antagonists revealed opposing effects on their lung colony-forming ability on intravenous injection. The authors concluded that EP4 promoted, whereas EP1 suppressed lung colony-forming ability. They extended the latter results by downregulating EP1 with shRNA and correlated the paucity of nuclear EP1 immunostaining with poor survival in breast cancer patients, implicating EP1 as a tumorsuppressor molecule. ${ }^{48}$ In this study, we noted no significant effect on spontaneous lung metastasis with the currently used ONO EP1 antagonist. Nevertheless, these results should be taken into consideration in developing EP1 an- tagonists for clinical use in patients with potential risk of breast cancer.

EP4 appears to be a good therapeutic target in a few other cancer models. For example, treating mice with the present EP4 antagonist ONO-AE3-208 was shown to reduce experimental lung metastasis of Lewis Lung carcinoma cells given by the intravenous route and liver metastasis of MC26 colon carcinoma cells delivered by the intrasplenic route. ${ }^{38}$ In the former case, a reduced lung colonization by tumor cells in EP4 null mice suggested that EP4 expression by tumor as well as host cells may have contributed to the therapeutic effects of the EP4 antagonist. In this study, we have not excluded this possibility. Interestingly, EP4 was shown to be upregulated in human prostate cancer tissues during progression to castration resistance, and was validated as a potential therapeutic target for treating castration-resistant prostate cancer, using an EP4 overexpressing prostate cancer xenograft model 
a
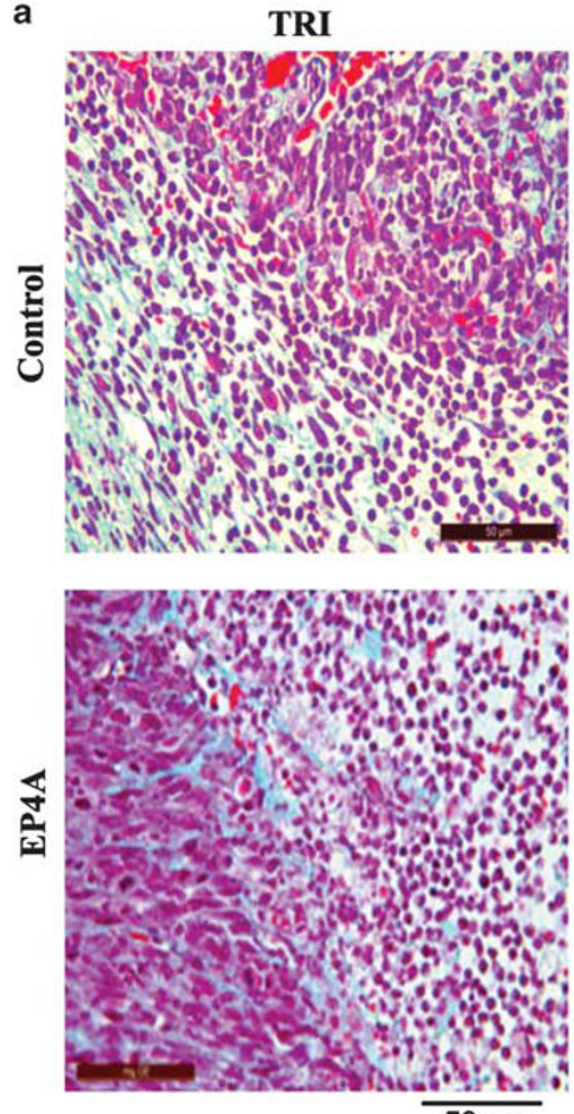

Ki67
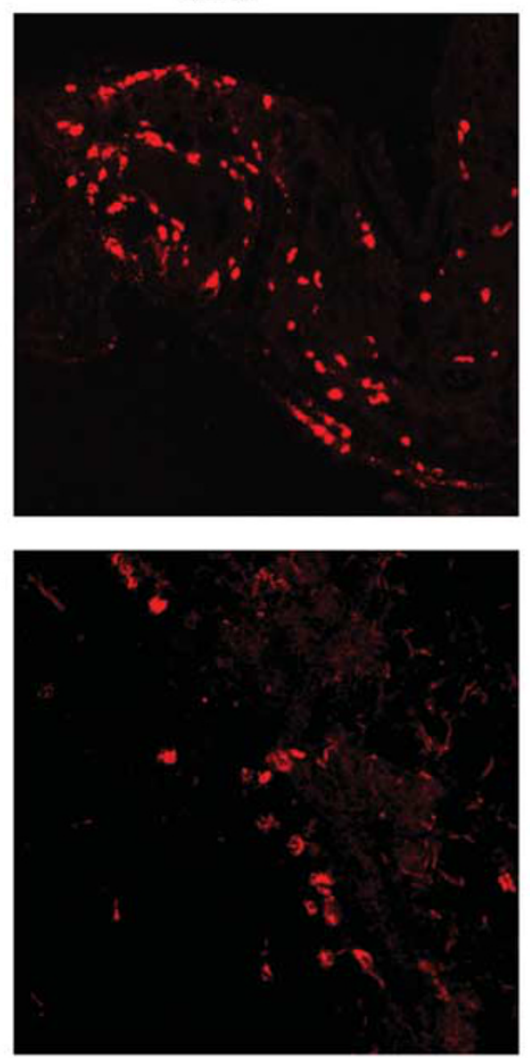

TUNEL
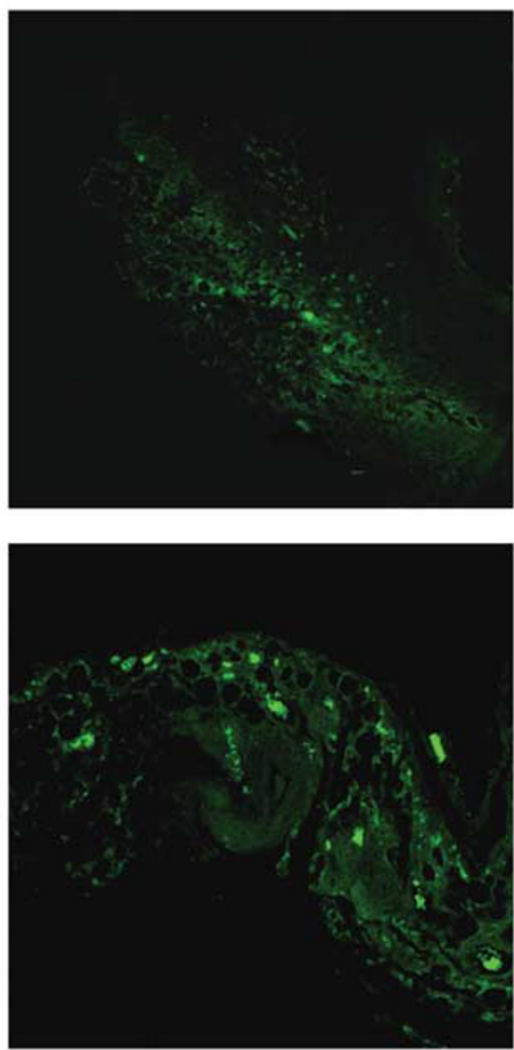

50um

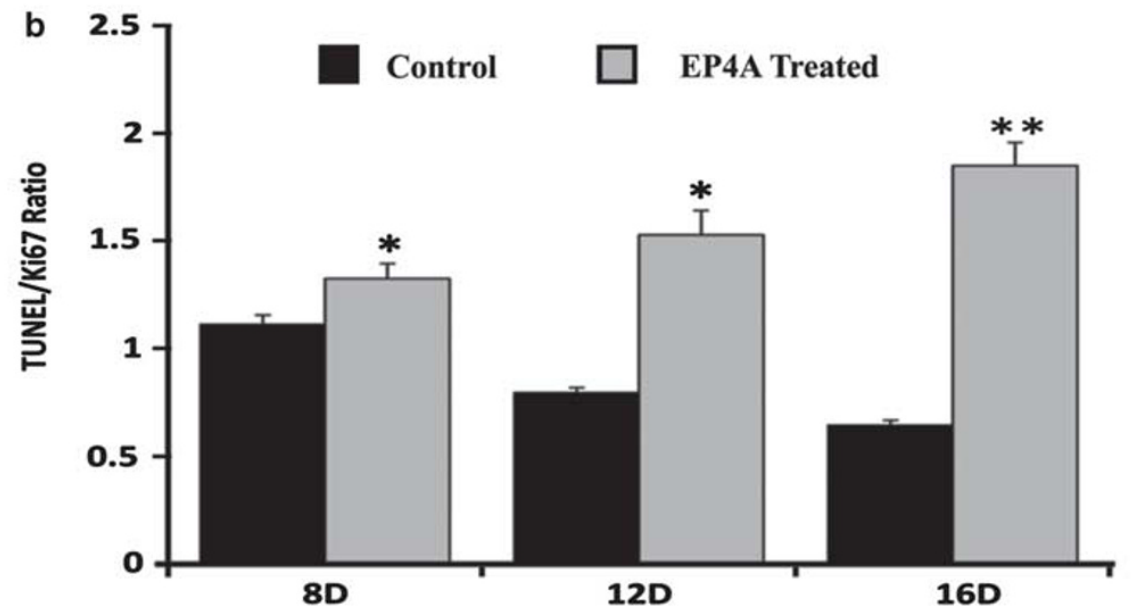

Figure 7 EP4 antagonist therapy increases the apoptotic/proliferative cell ratios in residual tumors. (a) Representative abundance of proliferative cells labeled for Ki67 marker (red), and apoptotic cells labeled for TUNEL (green) in situ are illustrated in serial sections for day 12 in vehicle-treated (control) and EP4A-treated mice. Images of corresponding H\&E-stained tumors in adjacent sections are shown on the left (scale bars are $50 \mu \mathrm{m}$, shown as insets). (b) The ratios of apoptotic/proliferative cells at different days following vehicle or EP4A therapy. Data represent mean $(n=12) \pm$ s.e., ${ }^{*} P<0.05$.; ${ }^{*} P<0.005$ comparing the two groups. The ratios showed a significant increase with time in EP4A-treated mice and decrease in control mice.

and therapy with the EP4 antagonist ONO-AE3-208. ${ }^{49}$ EP4 profiling of human breast cancer tissues is currently in progress in our laboratory to test its possible association with human breast cancer progression.

Both EP2 and EP4 are linked with a $G_{s}$ protein and thus activation of these receptors leads to an increase in intracellular cAMP followed by activation of protein kinase A. In addition, EP4 activation can also stimulate PI3K/AkT pathway, ${ }^{29}$ to promote PGE2-dependent cell survival. ${ }^{40}$ In this study, residual tumors in mice treated with indomethacin, celecoxib as well as the EP4 antagonist ONOAE3-208 showed a parallel reduction of AkT phosphorylation 
as well as VEGF-C or -D proteins, concomitant with an increase in apoptotic/proliferative cell ratios. As EP4 is the only EP receptor known to be linked with AkT activation, we believe that a blockade in EP4 signaling resulted from all the afore-mentioned therapies. The cyto-reductive effects of these therapies on the primary tumor can be attributed to both direct and indirect effects of the drugs on tumor cells, mediated by EP4 receptor inactivation: the direct effects, by blocking PGE2-dependent tumor cell survival; ${ }^{40}$ and the indirect effects because of a reduction in blood supply required for tumor cell oxygenation, proliferation and survival. This contention is supported by the findings that a reduction in tumor growth was preceded by a reduction in angiogenesis. Similar to the findings that EP4 was instrumental in stimulating the production of the lymphangiogenic factors VEGF-C and -D, we suggest that this is also true for the production of angiogenic factors by tumor cells. Direct effect of PGE2 on vascular and lymphatic endothelial cells in promoting the processes of angiogenesis and lymphangiogenesis are additional possibilities. In support, our preliminary data show that PGE2 produced by the present tumor cell line stimulates EP4 receptor on lymphatic endothelial cells in promoting tube formation in vitro. ${ }^{50}$

Molecular mechanisms responsible for EP4-mediated upregulation of lymphangiogenic factors in breast cancer cells remains to be investigated. Our preliminary findings reveal that endogenous PGE2-mediated upregulation of VEGF-C in the human breast cancer cell line MDA-MB-231 is dependent on the recruitment of the transcription factor NFKB in the VEGF-C promoter site. ${ }^{51}$ It has been shown that EP4mediated activation of PI3K/AkT pathway can cause downstream activation of ERK1/2 to induce the transcription factor early growth response factor (Efr) $-1^{29}$ that can upregulate VEGF-A in head and neck carcinoma. ${ }^{52}$ Studies are in progress to determine whether PI3K/AkT pathway is linked with EP4-mediated VEGF-C or D upregulation by recruitment of specific transcription factors.

There is compelling epidemiological evidence that intake of NSAIDs, including COX-2 inhibitors leads to significant risk reductions for the development of cancers in various organs including the breast. ${ }^{11,53}$ As a result of documented cardiovascular side effects of COX-2 inhibitors, ${ }^{25,26,54}$ alternative and safer therapies as single agent or in combination (as adjuvant) need to be tested in preclinical models. Based on our earlier data on the role of EP4 in multiple cellular events promoting breast cancer progression, our present preclinical data, and the fact that EP4 may have some redundancy for physiological functions shared with EP2, we suggest that EP4 may prove to be a safe target in the clinic for preventing and mitigating lymphatic metastasis of breast cancer in combination with other agents.

\section{ACKNOWLEDGEMENTS}

We thank Ms Lin Lu for technical help, Dr. Rabindra Bhattacharjee for technical advice and Dr Lynne Marie Postovit for statistical advice. This work was supported by grants of the Canadian Breast Cancer Foundation, Ontario Chapter and Ontario Institute for Cancer Research, Government of Ontario to PKL. GVG was the recipient of a Translational Breast Cancer Research Unit (TBCRU) fellowship.

\section{DISCLOSURE/CONFLICT OF INTEREST}

The authors declare no conflict of interest.

1. Williams CS, Mann M, DuBois RN. The role of cyclooxygenases in inflammation, cancer, and development. Oncogene 1999;18:7908-7916.

2. Wang MT, Honn KV, Nie D. Cyclooxygenases, prostanoids, and tumor progression. Cancer Metastasis Rev 2007;26:525-534.

3. Harris RE. . Humana Press: Totowa, NJ, 2003.

4. Liu $\mathrm{CH}$, Chang SH, Narko K, et al. Overexpression of cyclooxygenase-2 is sufficient to induce tumorigenesis in transgenic mice. J Biol Chem 2001;276:18563-18569.

5. Howe LR, Subbaramaiah K, Patel J, et al. Celecoxib, a selective cyclooxygenase 2 inhibitor, protects against human epidermal growth factor receptor 2 (HER-2)/neu-induced breast cancer. Cancer Res 2002;62:5405-54057.

6. Howe LR, Chang SH, Tolle KC, et al. HER2/neu-induced mammary tumorigenesis and angiogenesis are reduced in cyclooxygenase- 2 knockout mice. Cancer Res 2005;65:10113-10119.

7. Ristimaki A, Sivula A, Lundin J, et al. Prognostic significance of elevated cyclooxygenase-2 expression in breast cancer. Cancer Res 2002; 62:632-635.

8. Costa C, Soares R, Reis-Filho JS, et al. Cyclo-oxygenase 2 expression is associated with angiogenesis and lymph node metastasis in human breast cancer. J Clin Pathol 2002;55:429-434.

9. Zhang XH, Huang DP, Guo GL, et al. Coexpression of VEGF-C and COX2 and its association with lymphangiogenesis in human breast cancer. BMC Cancer 2008;8:4.

10. Ranger GS, Thomas $V$, Jewell $A$, et al. Elevated cyclooxygenase-2 expression correlates with distant metastases in breast cancer. Anticancer Res 2004;24:2349-2351.

11. Harris RE, Beebe-Donk J, Alshafie GA. Reduction in the risk of human breast cancer by selective cyclooxygenase-2 (COX-2) inhibitors. BMC Cancer 2006;6:27.

12. Lala PK, Parhar RS, Singh P. Indomethacin therapy abrogates the prostaglandin-mediated suppression of natural killer activity in tumorbearing mice and prevents tumor metastasis. Cell Immunol 1986;99:108-118.

13. Lala PK, Al-Mutter N, Orucevic A. Effects of chronic indomethacin therapy on the development and progression of spontaneous mammary tumors in C3H/HEJ mice. Int J Cancer 1997;73:371-380.

14. Rozic JG, Chakraborty C, Lala PK. Cyclooxygenase inhibitors retard murine mammary tumor progression by reducing tumor cell migration, invasiveness and angiogenesis. Int J Cancer 2001;93: 497-506.

15. Timoshenko AV, Xu G, Chakrabarti S, et al. Role of prostaglandin E2 receptors in migration of murine and human breast cancer cells. Exp Cell Res 2003;289:265-274.

16. Timoshenko AV, Lala PK, Chakraborty C. PGE2-mediated upregulation of iNOS in murine breast cancer cells through the activation of EP4 receptors. Int J Cancer 2004;108:384-389.

17. Timoshenko AV, Chakraborty C, Wagner GF, et al. COX-2-mediated stimulation of the lymphangiogenic factor VEGF-C in human breast cancer. Br J Cancer 2006;94:1154-1163.

18. Pepper MS, Tille JC, Nisato R, et al. Lymphangiogenesis and tumor metastasis. Cell Tissue Res 2003;314:167-177.

19. Vleugel MM, Bos R, van der GP, et al. Lack of lymphangiogenesis during breast carcinogenesis. J Clin Pathol 2004;57:746-751.

20. Van dA I, Van den Eynden GG, Colpaert CG, et al. Tumor lymphangiogenesis in inflammatory breast carcinoma: a histomorphometric study. Clin Cancer Res 2005;11:7637-7642.

21. Bhattacharjee RN, Timoshenko AV, Cai J, et al. Relationship between cyclooxygenase-2 and human epidermal growth factor receptor 2 in vascular endothelial growth factor $C$ up-regulation and lymphangiogenesis in human breast cancer. Cancer Sci 2010;101:2026-2032.

22. van IV, Leidenius M, von SK, et al. VEGF-D in association with VEGFR-3 promotes nodal metastasis in human invasive lobular breast cancer. Am J Clin Pathol 2007;128:759-766. 
23. Timoshenko AV, Rastogi S, Lala PK. Migration-promoting role of VEGF$\mathrm{C}$ and VEGF-C binding receptors in human breast cancer cells. $\mathrm{Br} \mathrm{J}$ Cancer 2007:97:1090-1098.

24. Perrone G, Santini D, Vincenzi B, et al. COX-2 expression in DCIS correlation with VEGF, HER-2/neu, prognostic molecular markers and clinicopathological features. Histopathology 2005;46:561-568.

25. Fitzgerald GA. Coxibs and cardiovascular disease. N Engl J Med 2004;35:1709-1711.

26. Graham DJ. COX-2 inhibitors, other NSAIDs, and cardiovascular risk: the seduction of common sense. JAMA 2006;296:1653-1656.

27. Breyer RM, Bagdassarian CK, Myers SA, et al. Prostanoid receptors: subtypes and signaling. Annu Rev Pharmacol Toxicol 2001;41:661-690.

28. Fujino $\mathrm{H}, \mathrm{Xu} \mathrm{W}$, Regan JW. Prostaglandin E2 induced functiona expression of early growth response factor-1 by EP4, but not EP2, prostanoid receptors via the phosphatidylinositol 3-kinase and extracellular signal-regulated kinases. J Biol Chem 2003;278:12151-12156.

29. Sugimoto $\mathrm{Y}$, Narumiya S. Prostaglandin E receptors. J Biol Chem 2007;282:11613-11617.

30. Kundu N, Ma X, Holt D, et al. Antagonism of the prostaglandin E receptor EP4 inhibits metastasis and enhances NK function. Breast Cancer Res Treat 2009;117:235-242.

31. Parhar RS, Lala PK. Prostaglandin E2-mediated inactivation of various killer lineage cells by tumor-bearing host macrophages. J Leukoc Biol 1988;44:474-484.

32. Sinha P, Clements VK, Fulton AM, et al. Prostaglandin E2 promotes tumor progression by inducing myeloid-derived suppressor cells. Cancer Res 2007;67:4507-4513.

33. Lala PK, Parhar RS. Eradication of spontaneous and experimental adenocarcinoma metastases with chronic indomethacin and intermittent IL-2 therapy. Int J Cancer 1993;54:677-684.

34. Kabashima K, Saji T, Murata $T$, et al. The prostaglandin receptor EP4 suppresses colitis, mucosal damage and CD4 cell activation in the gut. J Clin Invest 2002;109:883-893.

35. Kabashima K, Sakata D, Nagamachi M, et al. Prostaglandin E2-EP4 signaling initiates skin immune responses by promoting migration and maturation of Langerhans cells. Nat Med 2003;9:744-749.

36. Jadeski LC, Lala PK. Nitric oxide synthase inhibition by N(G)-nitro-Larginine methyl ester inhibits tumor-induced angiogenesis in mammary tumors. Am J Pathol 1999;155:1381-1390.

37. Trifan OC, Durham WF, Salazar VS, et al. Cyclooxygenase-2 inhibition with celecoxib enhances antitumor efficacy and reduces diarrhea side effect of CPT-11. Cancer Res 2002;62:5778-5784.

38. Yang $L$, Huang $Y$, Porta $R$, et al. Host and direct antitumor effects and profound reduction in tumor metastasis with selective EP4 receptor antagonism. Cancer Res 2006;66:9665-9672.

39. Belien JA, Somi S, de Jong JS, et al. Fully automated microvesse counting and hot spot selection by image processing of whole tumor sections in invasive breast cancer. J Clin Pathol 1999;52:184-192.
40. George RJ, Sturmoski MA, Anant $S$, et al. EP4 mediates PGE2 dependent cell survival through the PI3 kinase/AKT pathway. Prostaglandins Other Lipid Mediat 2007;83:112-120.

41. Barnes NL, Warnberg F, Farnie G, et al. Cyclooxygenase-2 inhibition: effects on tumor growth, cell cycling and lymphangiogenesis in a xenograft model of breast cancer. Br J Cancer 2007;96:575-582.

42. Iwata C, Kano MR, Komuro A, et al. Inhibition of cyclooxygenase-2 suppresses lymph node metastasis via reduction of lymphangiogenesis. Cancer Res 2007;67:10181-10189.

43. Kawamori T, Uchiya N, Nakatsugi S, et al. Chemopreventive effects of ONO-8711, a selective prostaglandin E receptor $\mathrm{EP}(1)$ antagonist, on breast cancer development. Carcinogenesis 2001;22:2001-2004.

44. Chang $\mathrm{SH}, \mathrm{Ai} \mathrm{Y}$, Breyer RM, et al. The prostaglandin E2 receptor EP2 is required for cyclooxygenase 2-mediated mammary hyperplasia. Cancer Res 2005;65:4496-4499.

45. Robertson FM, Simeone AM, Lucci A, et al. Differential regulation of the aggressive phenotype of inflammatory breast cancer cells by prostanoid receptors EP3 and EP4. Cancer 2010;116:2806-2814.

46. Hosono K, Suzuki T, Tamaki $\mathrm{H}$, et al. Roles of prostaglandin E2-EP3/EP4 receptor signaling in the enhancement of lymphangiogenesis during fibroblast growth factor-2-induced granulation formation. Arterioscler Thromb Vasc Biol 2011;31:1049-1058.

47. Ma X, Kundu N, Rifat S, et al. Prostaglandin E receptor EP4 antagonism inhibits breast cancer metastasis. Cancer Res 2006;66:2923-2927.

48. Ma X, Kundu N, loffe OB, et al. Prostaglandin E receptor EP1 suppresses breast cancer metastasis and is linked to survival differences and cancer disparities. Mol Cancer Res 2010;8:1310-1318.

49. Terada N, Shimizu Y, Kamba T, et al. Identification of EP4 as a potential target for the treatment of castration-resistant prostate cancer using a novel xenograft model. Cancer Res 2010;70:1606-1615.

50. Girish G, Radan L, Tutunea-Fatan E, et al. Role of prostaglandin E2 in breast cancer -associated lymphangiogenesis in an in vitro system. Proc Amer Assoc Cancer Res 2010;51:151-152, \# 636, 2010, Washington, DC

51. Bhattacharjee RN, Lala PK. Role of toll-like receptors in COX-2 mediated VEGF-C upregulation in breast cancer. Proc Amer Assoc Cancer Res 2009;50:371, \# 4139, 2009, Denver, CO.

52. Worden $B$, Yang $X P$, Lee $T L$, et al. Hepatocyte growth factor/scatter factor differentially regulates expression of proangiogenic factors through Egr-1 in head and neck squamous cell carcinoma. Cancer Res 2005;65:7071-7080.

53. Harris RE. Cyclooxygenase-2 (cox-2) blockade in the chemoprevention of cancers of the colon, breast, prostate, and lung. Inflammopharmacology 2009;17:55-67.

54. Kearney PM, Baigent C, Godwin J, et al. Do selective cyclo-oxygenase-2 inhibitors and traditional non-steroidal anti-inflammatory drugs increase the risk of atherothrombosis? Meta-analysis of randomised trials. BMJ 2006;332:1302-1308. 